\title{
Pemanfaatan Limbah Pertanian sebagai Alternatif Kantong Plastik di Dusun Mappasaile Kabupaten Maros, Sulawesi Selatan
}

\section{(Utilization of Agricultural Waste as an Alternative of Plastic Bags in Mappasaile, Maros Regency, South Sulawesi)}

\author{
Chaerunnisa Nur Fitrah", Arjun Azis, Hardianti Hasyim, Friska Mambela \\ Program Studi Kehutanan, Fakultas Kehutanan, Universitas Hasanuddin, Jl. Perintis Kemerdekaan Km.10, \\ Tamalanrea Indah, Makassar, Sulawesi Selatan 90245. \\ *Penulis Korespondensi: c.n.fitrah@gmail.com \\ Diterima Juni 2019/Disetujui Desember 2019
}

\begin{abstract}
ABSTRAK
Sampah merupakan salah satu permasalahan lingkungan yang krusial, terutama sampah kantong plastik dari hasil kegiatan berbelanja. Peningkatan produksi kantong plastik berbanding lurus dengan peningkatan jumlah penduduk. Tujuan dari kegiatan pengabdian ini adalah untuk meningkatkan pengetahuan dan keterampilan mitra dalam pengelolaan limbah pertanian di Dusun Mappasaile, Desa Limampoccoe, Kecamatan Cenrana, Kabupaten Maros. Dusun ini memiliki potensi limbah pelepah pisang dan sabut kelapa yang cukup tinggi dan belum termanfaatkan. Pelaksanaan kegiatan tediri atas beberapa tahapan, yaitu penyampaian materi, wawancara, praktik langsung pembuatan kertas, dan paper bag hingga monitoring kegiatan. Kegiatan ini dilakukan dengan menjadikan pemuda yang kurang produktif sebagai mitra dalam pelaksanaan kegiatan. Tingkat pengetahuan dan keterampilan mitra diukur dari pre-test dan post-test dengan menggunakan beberapa indikator/penilaian. Hasil kegiatan menunjukkan bahwa pengetahuan mitra meningkat dari $10 \%$ menjadi $76 \%$ dan keterampilan mitra meningkat dari $21 \%$ menjadi $81 \%$. Kegiatan ini memotivasi masyarakat terutama pemuda dalam pengelolaan limbah pertanian.
\end{abstract}

Kata kunci: Dusun Mappasaile, limbah pertanian, paper bag, pemuda

\begin{abstract}
Waste is one of the environmental problems, especially plastic bag waste that is difficult to decompose. One way to reduce the use of plastic bags is to use paper bags that made from agricultural waste (banana midrib and coconut husk waste). This community service activity aims to improve partner's knowledge and skills in agricultural waste managing (banana midrib and coconut husk waste) in Mappasaile Sub-village, Limampoccoe Village, Cenrana Sub-district, Maros District. The activity implementation consists of several stages, are transfer of knowledge, interviews, direct practice of making paper and paper bags, and monitoring of activities. The partners of this activity are young people who are less productive. The level of knowledge and skills of partners are measured from the pre-test and post-test using several indicators. The results of the activities show that partner knowledge increased from $10 \%$ to $76 \%$ and partner skills increased from $21 \%$ to $81 \%$. This activity motivates the community, especially youth, in managing agricultural waste and is expected to reduce plastic waste in the environment.
\end{abstract}

Keywords: agricultural waste, Mappasaile, paper bag, youth

\section{PENDAHULUAN}

Sampah merupakan salah satu permasalahan lingkungan yang krusial. Produksi sampah meningkat berbanding lurus dengan peningkatan jumlah penduduk. Kurangnya dasar hukum yang tegas, tempat pembuangan sampah yang tidak memadai dan belum tersedianya pengelolaan TPA dengan sistem yang tepat merupakan beberapa faktor yang mengakibatkan permasalahan pengelolaan sampah (Chaerul et al.
2007), salah satunya di Dusun Mappasaile. Dusun Mappasaile merupakan salah satu dari tujuh dusun yang terletak di Desa Limampoccoe, Kecamatan Cenrana, Kabupaten Maros (BPS 2015).

Permasalahan sampah anorganik yang paling sering ditemui adalah sampah kantong plastik yang tersebar luas di masyarakat terutama dari kegiatan berbelanja, padahal kantong plastik merupakan bahan yang sulit untuk terdekomposisi atau terurai. Kantong plastik masih 
menjadi bahan yang paling sering digunakan karena memiliki keunggulan dibanding material lainnya. Menurut Putra \& Yebi (2010), keunggulan plastik di antaranya kuat, ringan, fleksibel, tahan karat, dan tidak mudah pecah atau robek. Berbagai kebijakan telah diperlakukan oleh pemerintah dalam mengurangi produksi sampah kantong plastik, salah satunya adalah menggunakan alternatif kantong plastik seperti kantong kertas (paper bag). Kertas dari paper bag dapat dibuat dari bahan yang mengandung kadar selulosa yang tinggi, seperti kayu dan limbah pertanian.

Mata pencaharian masyarakat di Dusun Mappasaile didominasi pada bidang pertanian dan perkebunan seperti padi sawah, kelapa, dan pisang. Luas daerah perkebunan pisang dan kelapa mencapai 32 ha dari 2363,7 ha luas keseluruhan wilayah Desa Limampoccoe dengan produksi berkisar 2 ton/tahun (BPS 2018). Pemanfaatan pisang dan kelapa hanya difokuskan pada buahnya saja sehingga batang ataupun pelepah pisang dan sabut kelapa belum termanfaatkan. Pemanfaatan pelepah pisang dan sabut kelapa yang dilakukan masyarakat berkisar kurang dari 1\% (BPS 2017; BPS 2018) dan selebihnya dibiarkan sebagai limbah (agricultural waste). Limbah pertanian tersebut dapat dijadikan sebagai solusi dalam mengurangi produksi sampah seperti paper bag (Bahri 2015). Metode pengelolaan yang tepat diperlukan untuk memanfaatkan limbah pertanian tersebut.

Pengelolaan limbah pertanian dapat melibatkan peran masyarakat terutama terhadap pemuda yang kurang produktif. Pemuda merupakan faktor pendukung yang dapat memotivasi semua elemen masyarakat dalam melakukan perubahan (agent of change) dalam mengatasi masalah lingkungan. Pemuda di sini mengacu pada Undang-undang No. 4 Tahun 2009 tentang kepemudaan adalah warga negara Indonesia yang berusia 16-30 tahun. Tingginya jumlah pemuda di Dusun Mappasaile dapat menjadi salah satu modal dalam melaksanakan upaya tersebut. Berdasarakan data BPS pada tahun 2018 di Desa Limapoccoe terdapat sekitar 490 orang $(20 \%)$ pemuda dari 2.251 orang di mana kebanyakan merupakan buruh bangunan dan penggangguran. Oleh karena itu, kegiatan pengabdian ini bertujuan untuk meningkatkan pengetahuan dan keterampilan pemuda yang kurang produktif dengan melakukan pengelolaan limbah pertanian berupa inovasi paper bag yang terbuat dari campuran atau kombinasi limbah pelepah pisang dan sabut kelapa sehingga mampu mengurangi produksi sampah kantong plastik di Dusun Mappasaile.

\section{METODE PELAKSANAAN KEGIATAN}

\section{Waktu dan Tempat}

Kegiatan ini dilaksanakan pada bulan AprilJuni 2019, yang berlokasi di Dusun Mappasaile, Desa Limapoccoe, Kecamatan Cenrana, Kabupaten Maros, Sulawesi Selatan. Partisipan dari kegiatan ini adalah mitra yang berasal dari pemuda yang kurang produktif.

\section{Bahan dan Alat}

Bahan yang digunakan dalam kegiatan adalah limbah pelepah pisang dan sabut kelapa yang diperoleh dari kebun milik masyarakat setempat, $\mathrm{NaOH}$ atau soda api, tepung tapioca, dan air. Peralatan yang digunakan adalah peralatan memasak (panci dan pengaduk), saringan, cetakan kayu berukuran 80 × $50 \mathrm{~cm}$, tripleks atau flat seng, gunting, dan blender.

\section{Metode Pelaksanaan Kegiatan}

Program ini dilaksanakan dengan tahapan sebagaimana yang diperlihatkan skema pada Gambar 1.

\section{Pengumpulan Informasi dan Penyampaian Materi}

Pengumpulan informasi dilakukan dengan metode wawancara kepada mitra. Pengumpulan informasi ini bertujuan untuk mengetahui pengetahuan dan keterampilan awal yang dimiliki mitra sebelum mengikuti kegiatan. Penyampaian materi dilakukan dengan metode fun learning diikuti dengan pengenalan alat dan bahan yang digunakan, serta dilanjutkan dengan praktik pembuatan paper bag.

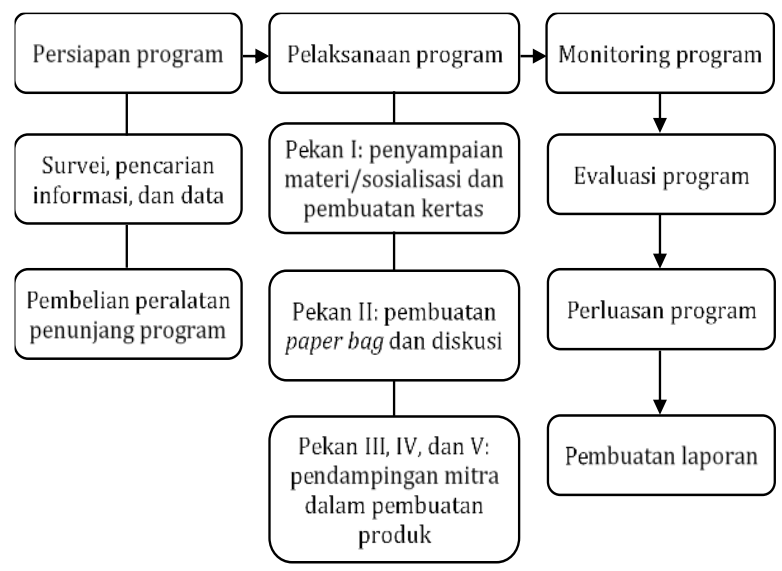

Gambar 1 Tahapan pelaksanaan kegiatan. 


\section{Pendampingan Mitra dan Evaluasi}

Pendampingan ini dilakukan untuk mengetahui penguasaan materi yang diberikan kepada mitra melalui praktik langsung dan menjadi tolok ukur keberhasilan pelaksanaan kegiatan. Pendampingan ini terbagi dua, yaitu pendampingan dalam pembuatan kertas dan paper bag. Kegiatan evaluasi dilakukan dengan melakukan wawancara untuk mengetahui pengetahuan dan keterampilan mitra selama mengikuti kegiatan.

\section{Monitoring dan Perluasan Kegiatan}

Monitoring kegiatan dengan secara tidak langsung berada di lokasi kegiatan (jarak jauh) bertujuan untuk melihat kegiatan mitra selama tim pengabdi tidak berada di lokasi kegiatan (kembali tidak produktif atau tetap dilaksanakan). Perluasan kegiatan dilakukan dengan melakukan publikasi ke media massa ataupun media online (media sosial).

\section{Analisis Data}

Peningkatan pengetahuan dan keterampilan mitra diukur dengan menggunakan beberapa indikator yang telah ditetapkan. Pengunaan indikator dilakukan pada wawancara tahap awal (tahap 1), pelaksanaan kegiatan (tahap 2), dan setelah kegiatan (tahap 3). Perhitungan peningkatan pengetahuan (PP) dan keterampilan (PK) mitra dianalisis untuk menentukan tingkat keberhasilan kegiatan.

$$
\begin{gathered}
\mathrm{PP}=\frac{\text { Capaian indikator pengetahuan }}{\text { jumlah indikator }} \times 100 \% \\
\mathrm{PK}=\frac{\text { Capaian indikator keterampilan }}{\text { jumlah indikator }} \times 100 \%
\end{gathered}
$$

\section{HASIL DAN PEMBAHASAN}

\section{Pengumpulan Informasi dan Penyampaian Materi}

Pengumpulan informasi telah dilakukan dengan wawancara kepada enam orang mitra tetap yang terdiri atas dua orang laki-laki dan empat orang perempuan. Keenam mitra memiliki rentang usia 15-24 tahun dan sebagian besar merupakan pelajar tingkat menengah atas. Kebanyakan kegiatan mitra sebelumnya tidak terlalu produktif. Hal ini dikarenakan kegiatan yang dilakukan untuk menghabiskan waktu adalah bermain gadget.

Pengumpulan informasi dengan wawancara mengenai dua topik utama, yaitu pengetahuan membuat kertas dan pemanfaatan limbah. Hasil wawancara menunjukkan semua mitra tidak mengetahui dan belum pernah melakukan pemanfaatan limbah pelepah pisang dan sabut kelapa. Hal ini merupakan tolak ukur mengenai masih kurang produktifnya mitra dan masih minimnya pengetahuan serta keterampilan mitra dalam memanfaatkan limbah.

Penyampaian materi dilakukan sebagai bentuk sosialisasi kepada mitra. Kegiatan pemberdayaan ini merupakan bentuk pengajaran secara informal dilakukan dengan metode fun learning. Materi yang disampaikan adalah permasalahan sampah kantong plastik yang terjadi saat ini, kegiatan dan peran pemuda dalam menjaga lingkungan. Materi ini kebanyakan dilakukan dengan menunjukkan foto dan video yang bertujuan agar kegiatan tidak terlalu terkesan seperti pengajaran secara formal. Pengenalan kegiatan dilakukan dengan menunjukkan produk yang akan dihasilkan, yaitu paper bag serta potensi pengembangan inovasi produk baik dari segi pewarnaan maupun pengembangan produk ke bentuk lainnya. Pengenalan alat dan bahan dilakukan dengan menunjukkan secara langsung dan cara penggunaannya seperti pada Gambar 2.

\section{Proses Pembuatan Paper Bag}

Kegiatan dilaksanakan dengan melibatkan mitra secara aktif dalam setiap proses pembuatan. Mitra dalam kegiatan ini berjumlah 6 orang. Kegiatan dilakukan di salah satu rumah mitra yang berpartisipasi dengan mempertimbangkan lokasi yang cukup dekat dengan sumber bahan baku produk. Kegiatan ini dibagi menjadi dua tahapan utama, yaitu pembuatan kertas dan paper bag. Kegiatan ini menunjukkan antusiasme masyarakat yang cukup tinggi oleh mitra mulai dari proses pengambilan bahan baku sampai dengan pada tahapan akhir pembuatan

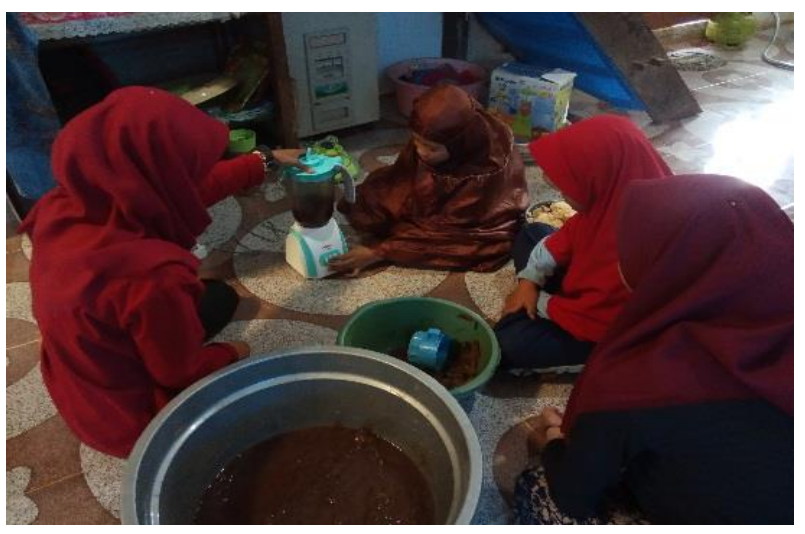

Gambar 2 Penyampaian materi dan pengenalan alat. 
produk. Pembuatan kertas yang dilakukan masyarakat pada awal kegiatan masih memiliki kualitas tidak terlalu baik, tetapi selama kegiatan pendampingan dilakukan terjadi peningkatan kualitas kertas dan paper bag yang dihasilkan secara signifikan.

\section{Pembuatan Kertas}

Pembuatan paper bag dilakukan dengan persiapan bahan baku limbah pertanian (pelepah pisang dan sabut kelapa) yang kemudian dibagi menjadi potongan-potongan kecil. Potonganpotongan limbah yang masih basah dilakukan pengeringan di bawah sinar matahari untuk mengurangi kadar air dari limbah sehingga rendemen yang dihasilkan lebih banyak (Gambar3). Setelah kering, potongan-potongan tersebut di masak pada panci yang berbeda selama 1 jam, kemudian ditambah $\mathrm{NaOH} /$ soda api dengan perbandingan $100 \mathrm{~g} \mathrm{NaOH}$ untuk $10 \mathrm{~kg}$ bahan baku limbah. Penggunaan $\mathrm{NaOH}$ berfungsi sebagai pemisah antara lignin dan selulosa pada serat limbah. Karena $\mathrm{NaOH}$ dan air jika dicampurkan akan menjadi basa kuat, maka hasil pencampuran serat dengan $\mathrm{NaOH}$ tersebut disimpan selama 24 jam pada wadah plastik atau baskom (Mufridayati et al. 2013). Setelah itu dicuci bersih dan diblender hingga menghasilkan serat yang terlihat halus (Gambar 4). Serat yang telah halus pada pelepah pisang dan sabut kelapa

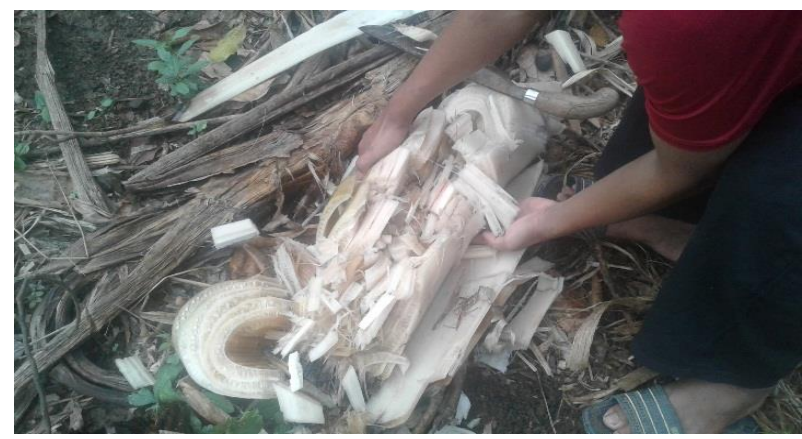

a disaring kemudian dicampur dengan perbandingan 10:1. Perbandingan ini bertujuan agar kertas yang dihasilkan lebih kuat dan halus. Serat selanjutnya dicampur dengan lem kanji dengan perbandingan $1 \mathrm{~kg}$ lem kanji untuk $10 \mathrm{~kg}$ serat, kemudian dicampur hingga merata dan dicetak menggunakan cetakan kayu. Hasil cetakan dikeringkan selama 24 jam dan akan terbentuk lembaran kertas yang siap dijadikan paper bag.

Produksi kertas yang dapat dilakukan oleh mitra adalah 4 lembar kertas berukuran A2 dengan bahan baku yang dibutuhkan sebanyak 5 kg pelepah pisang kering dan $500 \mathrm{~g}$ sabut kelapa (Gambar 5). Kondisi cuaca yang tidak mendukung dapat memperlambat proses produksi kertas.

\section{Pembuatan Paper Bag}

Pembuatan paper bag dilakukan dengan menggunakan metode origami sederhana. Pembuatan ini juga membutuhkan bantuan dari lem kertas. Paper bag yang dibuat terdiri dari atas tiga macam ukuran, yaitu ukuran besar $(40 \times 30$ $\mathrm{cm})$, sedang $(30 \times 20 \mathrm{~cm})$, dan kecil $(25 \times 10 \mathrm{~cm})$ (Gambar 6).

\section{Tingkat Pengetahuan Mitra}

Kemampuan seseorang dalam mengingat suatu (ide dan fenomena) yang diajarkan dapat menjadi pengetahuan. Adanya pengetahuan akan

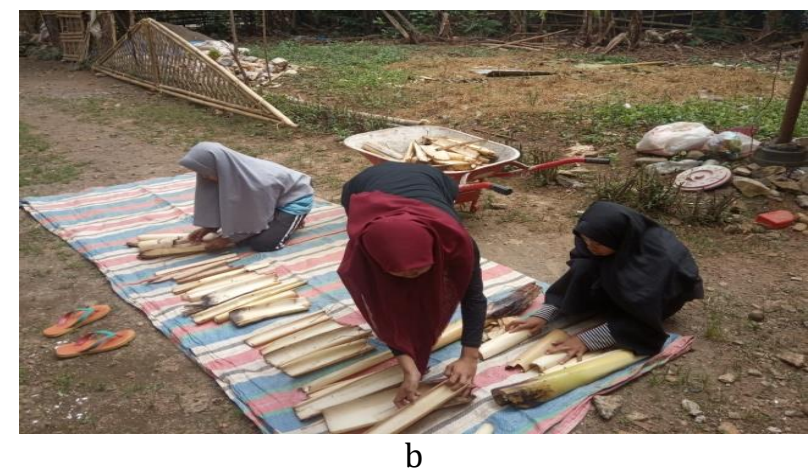

Gambar 3 Persiapan bahan; a) Pemotongan pelepah pisang dan b) Penjemuran pelepah pisang.

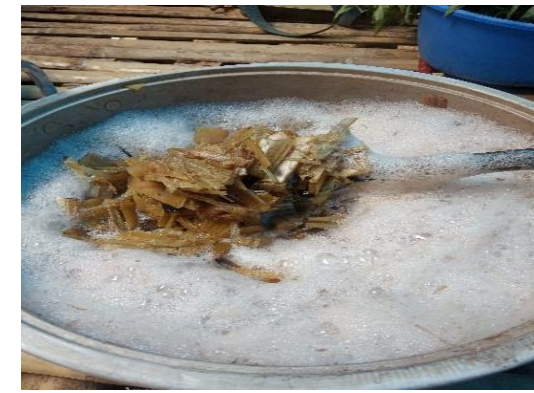

a

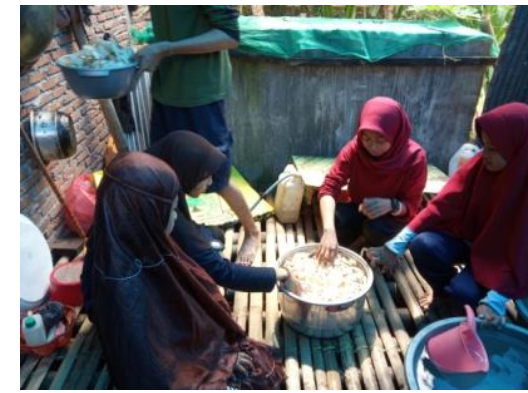

$\mathrm{b}$

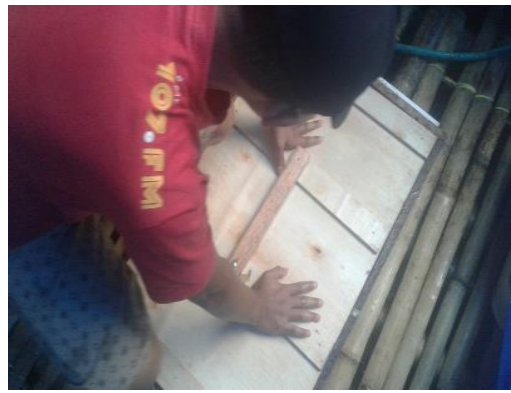

c

Gambar 4 Proses pembuatan kertas; a) Perebusan bahan baku; b) Pencucian bahan baku; dan c) Pencetakan bahan baku. 


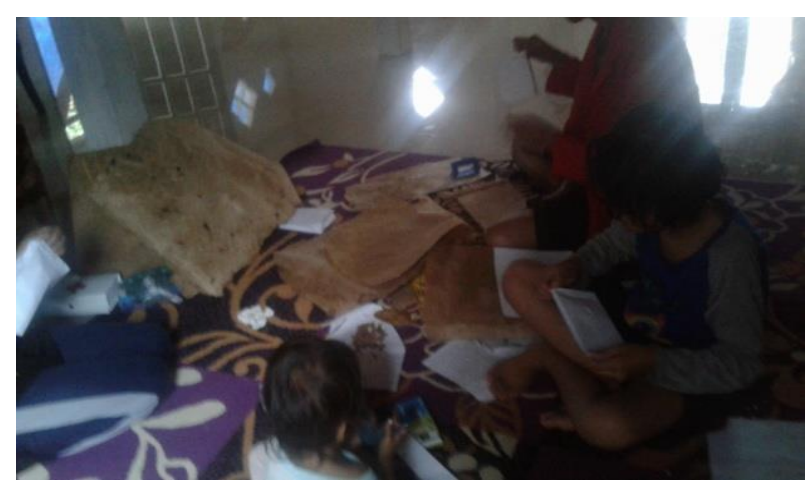

a

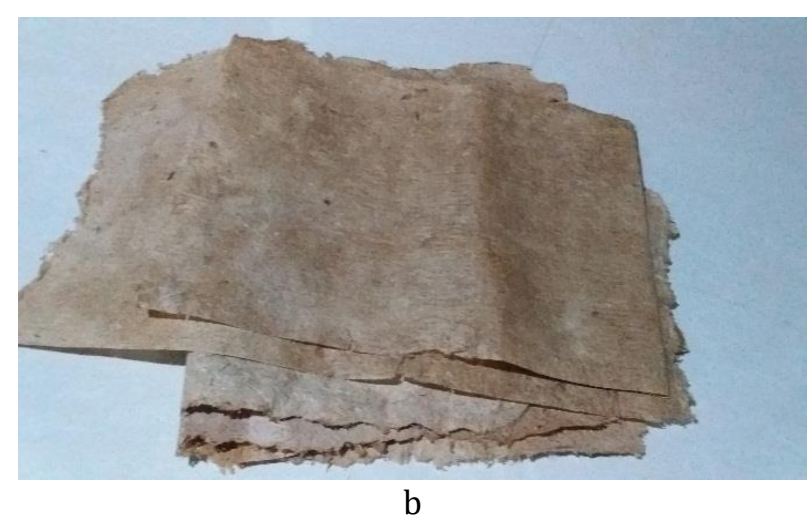

$\mathrm{b}$

Gambar 5 Proses pembuatan paper bag (a) dari kertas berbahan pelepah pisang dan sabut kelapa (b).

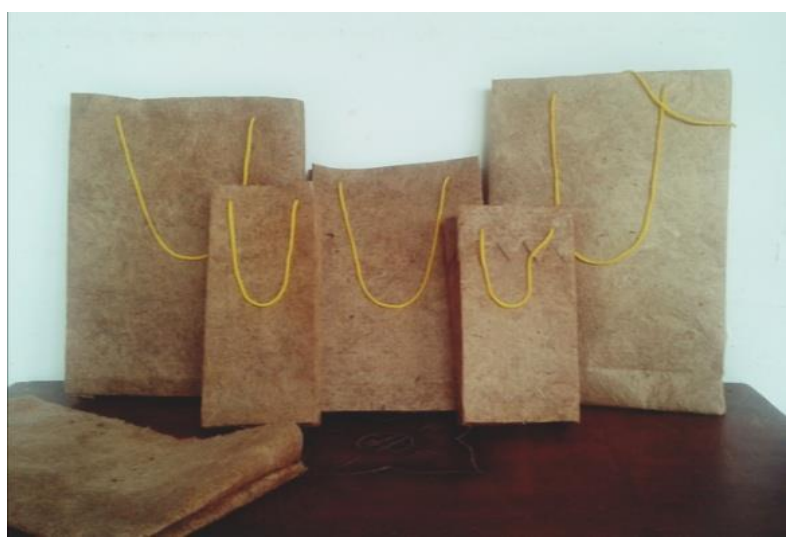

Gambar 6 Paper bag dari pelepah pisang dan sabut kelapa.

membentuk tindakan pengelolaan sampah yang berhubungan dengan kemampuan intelektual seseorang (Lestari et al. 2010). Tingkat pengetahuan mitra selama mengikuti kegiatan menunjukkan adanya peningkatan dalam setiap kegiatan yang dilakukan. Beberapa hal yang dijadikan tolak ukur adalah pemahaman dalam mengenali alat yang digunakan, pemahaman dalam membuat perbandingan bahan dalam pembuatan paper bag yang sudah cukup baik, urutan proses pembuatan kertas yang mulai lebih teratur dan sistematis, munculnya kesadaran dan ide dalam usaha menjaga lingkungan sekitar dari hasil tes yang diberikan dan lain sebagainya. Peningkatan pengetahuan dari awal sampai akhir kegiatan adalah masing-masing sebesar 10, 52, dan 76\% (Gambar 7). Tingkat pengetahuan yang cukup tinggi akan mengakibatkan mitra dapat mengurangi penyebaran sampah dan dilakukan dalam kehidupan seharihari. Hal ini sejalan dengan penelitian yang dilakukan oleh Riswan et al. (2011) menyatakan informasi atau pengetahuan adalah syarat penting bagi sikap, jadi sikap bukan hanya perasaan mendukung atau tidak mendukung perilaku, namun juga menyangkut estimasi akan hasil dari perilaku tersebut. Sikap yang tidak baik bisa disebabkan oleh kurangnya pengetahuan tentang pengolahan sampah/limbah.

\section{Tingkat Keterampilan Mitra}

Pembelajaran keterampilan adalah pembelajaran sebagai suatu rangkaian event (kejadian, peristiwa, kondisi, dan lain-lain) yang secara sengaja dirancang untuk memengaruhi mitra, Keterampilan merupakan salah satu unsur psikomotorik dalam mengembangkan kemampuan seseorang. Berdasarkan tahapan yang dilakukan, tingkat keterampilan mitra dalam kegiatan ini meningkat. Peningkatan keterampilan mitra dilihat dari penggunaan alat dan bahan, pembuatan paper bag dengan teknik melipat kertas dan keterampilan membuat kertas. Keterampilan mitra selama mengikuti kegiatan secara terurut adalah sebesar 21, 65, dan 81\% (Gambar 8). Peningkatan keterampilan mitra dapat membantu dalam meningkatkan pemanfaatan terhadap limbah. Hal ini sejalan dengan penelitian Arico \& Jayanthi (2017), yang melakukan pelatihan pengolahan limbah plastik menjadi produk bernilai ekonomis yang memberikan dampak positif bagi masyarakat. Peningkatan pengetahuan dan keterampilan mitra dalam pengelolaan limbah pertanian memiliki potensi untuk dikembangkan menjadi produk lain selain paper bag. Penerapan penggunaan paper bag sebagai alternatif pengganti kantong plastik dalam kegiatan berbelanja telah dilakukan beberapa masyarakat dan juga merupakan salah satu tolok ukur dari tujuan program.

\section{Keberlanjutan Program}

Keberlanjutan program sangat penting dalam setiap program pengabdian kepada masyarakat. Program yang dirancang dalam waktu yang singkat tidak akan berjalan sempurna secara 


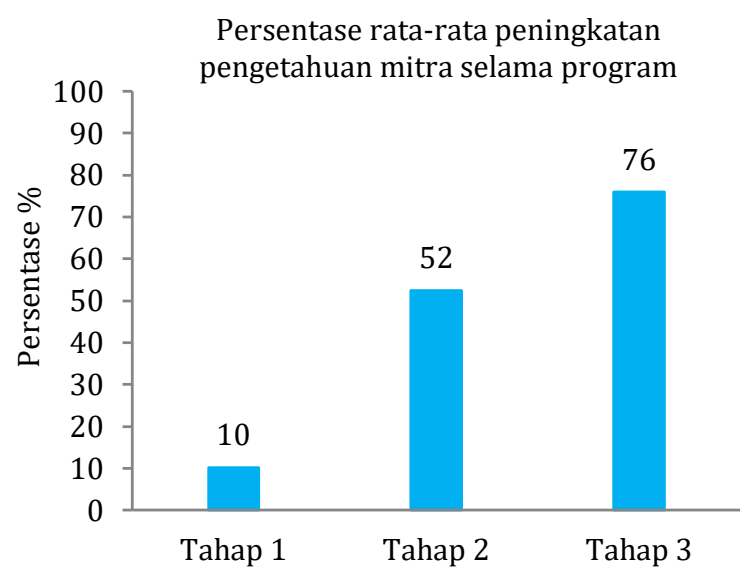

Gambar 7 Grafik rata-rata tingkat pengetahuan mitra.

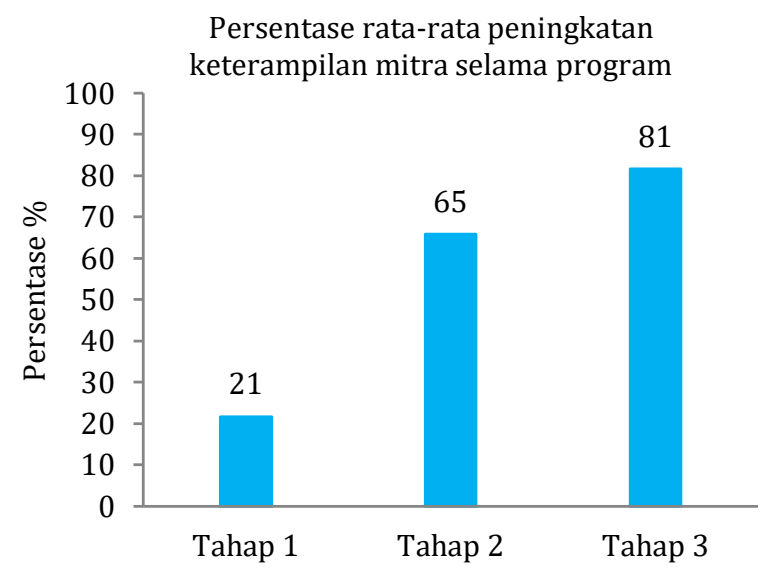

Gambar 8 Grafik rata-rata tingkat keterampilan mitra.

keseluruhan tanpa adanya keberlanjutan dan kerja sama dengan berbagai pihak. Keberlanjutan program akan menjadi tanggung jawab mitra dalam pelaksanaannya (terbentuknya masyarakat kader). Keberlanjutan dari program ini nantinya akan diarahkan dengan melakukan kerja sama antara lembaga kemasyarakatan yang ada di desa tersebut, masyarakat dan mahasiswa yang ingin mengikuti program ini melalui komunikasi dan kunjungan. Hal ini agar adanya motivasi dari pihak-pihak lain dalam menjadikan program ini sebagai unit pelatihan yang dapat membantu dalam menyebarluaskan pengetahuan mengenai pengolahan limbah. Produk dari program juga akan dikembangkan bukan hanya dalam satu produk, namun bervariasi dari ukuran dan warna serta bernilai estetika.

\section{SIMPULAN}

Kegiatan pengabdian yang dilakukan selama tiga bulan di Dusun Mappasaile, Kabupaten Maros yang berfokus pada pengelolaan limbah pertanian guna mengurangi produksi sampah kantong plastik. Mitra sudah mampu membuat kertas dan paper bag dengan berbagai ukuran. Hasil evaluasi kegiatan menunjukkan adanya peningkatan pengetahuan dan keterampilan mitra dengan tingkat keberhasilan di atas $70 \%$. Hal ini menunjukkan bahwa kegiatan ini dapat memberikan motivasi kepada masyarakat terutama pemuda dalam pengelolaan limbah pertanian.

\section{UCAPAN TERIMA KASIH}

Ucapan terima kasih kepada Kementerian Riset, Teknologi dan Pendidikan Tinggi (Kemenristekdikti) atas hibah yang diberikan melalui Kegiatan Kreativitas Mahasiswa (PKM) tahun 2019, sehingga kegiatan ini dapat terlaksana dengan baik.

\section{DAFTAR PUSTAKA}

Arico Z, Jayanthi S. 2017. Pengolahan Limbah Plastik Menjadi Produk Kreatif Sebagai Peningkatan Ekonomi Masyarakat Pesisir. MARTABE: Jurnal Pengabdian Masyarakat. 1(1): 1-6. https://doi.org/10.31604/ jm.v1i1.224

Bahri S. 2015. Pembuatan Pulp dari Batang Pisang. Jurnal Teknologi Kimia Unimal. 4(2): 36-50. https://doi.org/10.29103/jtku. v4i2.72

[BPS] Badan Pusat Statistik. 2015. Dusun Mappasaile. Maros (ID): BPS Kabupaten Maros.

[BPS] Badan Pusat Statistik. 2017. Maros dalam Angka 2017. Kerjasama Badan Pusat Statistik dengan Bappeda Kabupaten Maros. Seksi Integrasi Pengolahan Data dan Diseminasi Statistik, Maros (ID).

[BPS] Badan Pusat Statistik. 2018. Kecamatan Cenrana dalam Angka 2017. Maros (ID): BPS Kabupaten Maros

Chaerul M, Tanaka M, Shekdar AV. 2007. Municipal Solid Waste Management in Indonesia: Status and the Strategic Actions. Journal of The faculty of Environmental Science And Technology Okayama University. 12(1): 41-49.

Lestari AP, Soeaidy MS, Said A. 2010. Program Inovasi Pengelolaan Sampah di Kota Malang. 
Jurnal Administrasi Publik (JAP). 2(3): 571577.

Mufridayati, Syahrul H, Tua RS. 2013. Pembuatan Dan Karakterisasi Kertas dari Campuran Serat Jambul Nanas dan Serat Jerami Padi. Jurnal Saintika Fisika. 1(3): 1-6.

Putra HP, Yebi Y. 2010. Studi Pemanfaatan Sampah Plastik Menjadi Produk dan Jasa Kreatif. Jurnal Sains dan Teknologi
Lingkungan. 2(1): 21-31. https://doi.org/ 10.20885/jstl.vol2.iss1.art3

Riswan, Sunoko HR, Hadiyarto A. 2011. Pengelolaan Sampah Rumah Tangga di Kecamatan Daha Selatan. Jurnal Ilmu Lingkungan. 9(1): 31-39. https://doi.org/ 10.14710/jil.9.1.31-38

Undang-Undang Nomor 4 Tahun 2009 Tentang Kepemudaan. 